\title{
A Novel Variant of HOXA10 gene, Ser19Cys, among Patients with Endometriosis and its Relationship with the Severity of the Disease
}

\author{
Pinda Hutajulu ${ }^{1 *}$, Djaswadi Dasuki ${ }^{2}$, Ahmad Hamim Sadewa $^{3}$, and Totok Utoro ${ }^{4}$
}

\author{
${ }^{1}$ Department of Obstetric and Gynaecology, Sudarso Hospital, Pontianak, Indonesia \\ ${ }^{2}$ Department of Obstetric and Gynaecology, Faculty of Medicine, Universitas Gadjah Mada, Indonesia \\ ${ }^{3}$ Departemen of Biochemistry, Faculty of Medicine, Universitas Gadjah Mada, Yogyakarta, Indonesia \\ ${ }^{4}$ Departemen of Anatomy Pathology, Faculty of Medicine, Universitas Gadjah Mada, Yogyakarta, \\ Indonesia
}

\begin{abstract}
Endometriosis is a gynecological disease associated with inherited genetic traits. HOXA10 gene which is expressed in uterine plays an important role in the pathogenesis of endometriosis. The protein affects the development of pinopodes as a biomarker of endometrial receptivity in endometriosis. The aim of this study is to examine if there is a mutation or polymorphism within HOXA10 gene among patients with endometriosis. Thirty twopatients and 32 healthy women were recruited as subjects of this study. The exon 2 of HOXA10 which covers most of coding region was amplified using PCR. The presence of a mutation or polymorphism was detected by direct seguencing. The distribution of genotype and allele was analyzed using Chi square test with $\mathrm{p}<0.05$ is considered as significantly different. A novel heterozygous variant within exon 2 of HOXA10 which substitute an adenine into thymine was detected at base position 55 . This missense alteration changed amino acid serine to cystein (Ser19Cys). Interestingly, this variant was detected in 12 endometriosis cases (38\%) but none in control. Patients carry HOXA10 Ser19Cys variant were associated with dismenorea and more frequent in stage I endometriosis. The role of this variant in the function of HOXA10 protein and frequency among Indonesians need to be clarified. We found a novel heterozygous HOXA10 gene variant, Ser19Cys.The genotype frequency is $38 \%$ among endometriosis patients but none in control. This variant found in patient with dismenore and endometriosis stage 1.
\end{abstract}

Key words: HOXA10 gene, endometriosis, Ser19Cys polymophism

\section{Introduction}

Endometriosis is a gynecological disease marked by the presence of endometrial tissue proliferation outside the uterine cavity and is usually associated with menstrual pain and infértility. One important cause of endometriosis is retrograde menstruation that causes deposition of endometrial tissue in the peritoneal cavity. Endometriosis is a disease that gains a lot of attention but its

\section{*Corresponding author:}

Pinda Hutajulu,

Department of Obstetric and Gineycology, Sudarso

Hospital, Pontianak, West Kalimantan, Indonesia

email : pd_hutajulu@yahoo.com exact ethiopathogenesis remains unknown. Infértility in endometriosis may occur at the time of pre implantation, implantation and post-implantation (Collette et al., 2006; Kim et al., 2007). Approximately $50 \%$ of women experiencing infértility were diagnosed as having endometriosis and when accompanied by pelvic pain or menstrual pain, the findings of endometriosis reached $80 \%$ (Kao et al., 2003). In 20 meta-analysis studies on the IVF-related outcomes from endometriosis patients concluded that either endometrial receptivity or the quality of oocytes or embryo influenced the declined pregnancy rates (Barnhart et al., 2002).

Endometrial eutopic of women with endometriosis is different from those without 
endometriosis, in which the endometrium with endometriosis can express aromatase, the enzyme that catalyzes the production of estradiol. Increasing estradiol in endometrium can interfere with the implantation process in which blastocysts are anatomically and physiologically invading the uterine wall(Bulun et al., 2000; Huhtinen, 2010). The process of implantation requires the synchronized of conceptus development and endometrial receptivity, initiated by the process of apposition, adhesion and invasion followed by the transformation of endometrium into decidual until the formation of the placenta (Wu et al., 2005).

HOXA10 gene is thought to play roles in regulating gene expression, morphogenesis, and differentiation in endometrial cells. Its expression is regulated by estrogen and progesterone(Daftary et al., 2002). Progesterone and estrogen regulate expression of HOXA10 in the endometrium, through the progesterone receptor (PR) and estrogen receptor (ER). HOXA10 expression affects the development of pinopodes as a biomarker of endometrial receptivity (Murphy, 2000; Adam et al., 2002; Quinn et al., 2008).

HOXA10 is required for the implantation process, directly acts to regulate cell adhesion molecules (CAM) such as ITGAVB3 (Taylor et al., 1999; Daftary et al., 2002). HOXA10 expression in the endometrium has increased during ovulation (Bagot et al., 2000). The inhibition of HOXA10 expression would dramatically reduce the number of pinopodes (Lee and Mayo, 2004; Achache and Revel, 2006). A slight decrease of HOXA10 expression is seen in luminal area, glands, and endothelium, but is reduced significantly in the area of endometrial stromal endometriosis (Gui et al., 1999; Wu et al, 2005; Matsuzaki et al, 2009). HOXA10 expression decreases in the endometrium's endometriosis and followed by a defect in the expression of the target of HOXA10 gene such as EMX-2 and B3 integrin (Bagot et al., 2000; Daftary et al., 2002).

Both HOXA10 and ITGAVB3 appear in the window of implantation in the human endometrium, and the expression decrease in women with endometriosis and infértility (Lessey et al., 1994; Taylor et al., 1997; Achache and Revel 2006; Klemmt et al., 2006) as well as with the profile(number and size) of pinopodes (Lee and Mayo, 2004; Achache and Revel, 2006). However, several other researchers reported that there was norelationship between these conditions. It was found that involvement of multiple genes interacting in the pathogenesis ofendometriosis, so endometriosis is called the complex disease and the overall pathogenesis is unknown.

Whether proteomic changes of HOXA10 and ITGAVB3 in the endometriosis are affected by genomic changes and whether the interaction of HOXA10 and ITGAVB3 affects pinopodes or is an incidence that is unrelated need to be known as the basic of treatment of endometriosis. The aim of this study are to detect the presence of mutation or polymorphism in the HOXA10 gene and to compare its frequency in endometriosis patients with that in control at the time of the window of implantation. Thus, whether regulation of HOXA10 gene is caused by genetic defect which lead to low expression and promote the pathogenic process of endometriosis could be explained.

\section{Materials and Methods}

During the period of June 2010 to December2011,32 patients with endometriosis were enrolled in this study as case group. All data and blood from women who underwent laparoscopic and hysteroscopic surgery in Dr. Sarjito General Hospital and Islamic Hospital of Klaten were obtained. Thirty two healthy women underwent minilaparotomic for tubectomi (MOW) surgery in Dr. Sarjito General Hospital were recruited as the control group. All patients had given their informed consent to participate and were willing to undergo surgery, blood sampling and data analysis. The protocol of this study has been approved by Ethical Research Committee of Medical and Health at Faculty of Medicine, Universitas Gadjah Mada, Yogyakarta. 
The data was collected in the same period between endometriosis patients with infértility and non-endometriosis and fértile patients. The control group was patients who underwent female sterilization. The data taken include dependent variables, independent variables and potential variables as confounding variables. The dependent variables were endometriosis and stage of endometriosis.

Five mililiters of blood withdrawn from subjects was DNA extracted using standard method of phenol chloroform describe elsewhere. To detect the presence of polymorphism in the endometriosis among patients and controls, polymerase chain reaction (PCR) was used followed by direct sequencing. Primers flanking exon 2 of HOXA10 gene were design based on sequencing provided by Genatlas (http://genatlas.medecine. univ-paris5.fr/) as follows : forward primer 5'-ATG GGA GAA ACG GAG GCA ATT C-3' and reverse primer 5'-AGT TCC TGG GCA GAG CCT GAA-3'. PCR was performed in a 30 ul mixture reaction including 2 ul ofDNA template, 15 ul of PCR master mix (Promega ${ }^{\circledR}$ ) containing Taq polymerase, $\mathrm{dNTPs}, \mathrm{MgCl} 2$ and PCR buffer, 1 ul of each primers and $11 \mathrm{ul}$ distilled water. PCR conditions consisted of initial denaturation at temperature of $95^{\circ} \mathrm{C}$ in $10 \mathrm{~min}$, followed by 35 cycles consisting of denaturation of $95^{\circ} \mathrm{C}$ in $45 \mathrm{sec}$, annealing of $59^{\circ} \mathrm{C}$ in $45 \mathrm{sec}$, and extension at a temperature of $72^{\circ} \mathrm{C}$ in $45 \mathrm{sec}$, and ended with a final extension at $72^{\circ} \mathrm{C}$ in $7 \mathrm{~min}$. The total time required was 1 h $56 \mathrm{~min}$. Direct sequencing were performed using ABI Prism 310® (Applied Biosystem, Omaha) and the results were analyzed using software provided by the same company. PCR products were visualized as a DNA band formed in the gelatin mold ( $2 \%$ agarose).

\section{Result}

The characteristic of subjects is shown in Table 1.

The average of mean body mass index and endometriosis history in family were similar between the two groups, but average
Table 1. Basic Characteristics of patients with Endometriosis and Control

\begin{tabular}{lccc}
\hline \multicolumn{1}{c}{ Variabel } & Endometriosis & Control & $\mathbf{P}$ \\
\hline Age & $33.31 \pm 0.93$ & 36 & 0.04 \\
BMI & $21.61 \pm 0.29$ & $22.49 \pm 0.56$ & 0.17 \\
Parity & $0.18 \pm 0.09$ & $2.75 \pm 0.14$ & 0.00 \\
Dismenore & & & \\
$\quad+$ & $24(75.0 \%)$ & $3(9.4 \%)$ & $0.001^{* *}$ \\
$\quad-$ & $8(25.0 \%)$ & $29(90.6 \%)$ & \\
Endo. Hystory & & & \\
$\quad+$ & $8(25 \%)$ & $3(9.38 \%)$ & 0.1 \\
$\quad$ & $24(75 \%)$ & $29(90.63 \%)$ & \\
\hline
\end{tabular}

$\mathrm{p} \leq 0.05$ Sig. **; $\mathrm{p}<0.1$ Sig. *

of age was higher in control group as women who want to undergo tubectomy usually have already many children. The frequency of dismenorea as a main symptom is higher in endometriosis group but parity is lower in infertile endometriosis group.

We identified a heterozygous variant in the HOXA 10 gene at position $55(\mathrm{~A}>\mathrm{T})$ leading to amino acid substitution from serine to cystein (Figure 1). This variant is novel because as our knowledge until the preparation of this manuscript, there was no previous report published in other journals and no data found both in Genebank and Genatlas on mutation and polymorphism database.

A genotype study of HOXA10 was carried out for all subjects. In this study it was discovered a variants in exon 2 of HOXA10 gene and after followed by sequencing the genes it found the base changes $(A>T)$ in the position $55 \mathrm{bp}$ in which the codon of AGT changed to TGT (Ser19Cys) or there was a change from amino acid of serine into systein in the position 19.

Analysis of Ser19Cys polymorphism HOXA10 with cinical characteristic in endometriosis groups showed that genetic variant were associated with dismenorea as a main complain in endometriosis, and its frequency was higher in patient with stage I endometriosis.Of the 32 patients with endometriosis it was found 12 patients with 

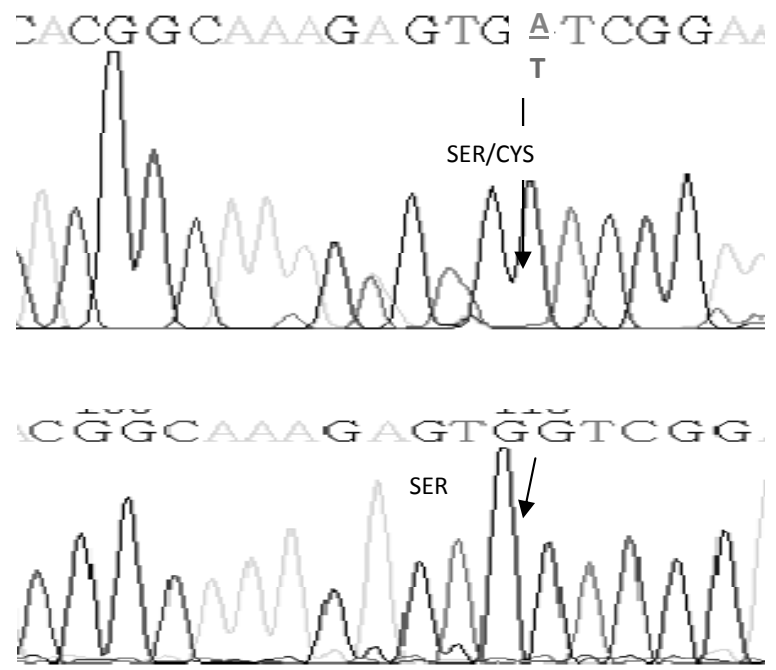

Figure 1. Direct sequencing reveled a variant in exon 2 of HOXA10 gene of a patient (top). It was found the adeninehas changed into thymineat position 55 (arrow) in which the codon of AGT changed to TGT (AGT $\rightarrow$ TGT) or changes in the amino acid Serine to Cystein (Ser19Cys). The bottom DNA sequence of a control shows no found the adeninechanged into thymine

variant $(38 \%)$ and it was not found in the controls. To clarify whether this variant is a mutation or polymorphism required in a study population and of protein study. It is also not clear whether this variant is specific to the population in Indonesia because there is no researcher reported it.

\section{Discussion}

Endometriosis is a disease that is often encountered and associated with genetic factors. One of expected genes playing a role in the pathogenesis of endometriosis is HOXA10 gene. HOXA10 gene is an essential gene to identity the growth of reproductive organsby regulating the proliferation of endometrial stromal cells and the morphogenesis of endometrial epithelial cell (Achache and Revel, 2006). HOXA10 gene also functions to maintain cell adhesion molecules like ITGAVB3. Disorders of the expression of HOXA10 cause disturbances on the process of epithelialization and decidualization by interfering with the expression of HOXA10 gene target as ITGAVB3 and the expression of pinopodes. Disorders of the expression of pinopode cause disruptions in the process of apposition and disruption on the expression of ITGAVB3 that cause disruptions of the adhesion and invasion process. Disorders of HOXA10 expression can be caused by polymorphisms, mutations or methylation (Wu et al., 2005; Kim et al., 2007; Wu et al., 2008).

Direct sequencing detected a variant in exon 2 of HOXA10 gene at position 55 which change adenine to thymine (A55T) leads to substitution of serine to cystein at amino acid position 19 (ser19cys). Of the 32 patients with endometriosis it was found 12 patients with change in nucleic acid (38\%) and it was not found in the controls. It is not clear whether this variant is a mutation or polymorphism required in a study of protein. It is also not

Table 2. Characteristic of individuals with and without Ser19Cys polymorphism of HOXA10 gene among endometriosis' patients

\begin{tabular}{lccc}
\hline \multicolumn{1}{c}{ Variabel } & $\begin{array}{c}\text { Polymorphism }+ \\
\mathbf{n = 1 2}\end{array}$ & $\begin{array}{c}\text { Polymorphism } \\
\mathbf{n = 2 0}\end{array}$ & P value \\
\hline Mean Age & $32 \pm 1.24$ & $34.05 \pm 1.28$ & 0.28 \\
Mean BMI & $21.53 \pm 1.81$ & $21.62 \pm 1.65$ & 0.84 \\
Dismenore +/- & $8 / 4$ & $16 / 4$ & 0.4 \\
Mean Menars & $15.08 \pm 0.66$ & $14.25 \pm 1.61$ & 0.10 \\
Endo. Hystory (+/-) & $3 / 9$ & $5 / 15$ & 1.00 \\
Stage I & 5 & 3 & 0.27 \\
\multicolumn{1}{c}{ II } & 3 & 10 & \\
III & 0 & 1 & \\
IV & 4 & 6 & \\
\hline
\end{tabular}

p $\leq 0.05$ Sig. **; $p<0.1$ Sig. * 
clear whether this variant is specific to the population in Indonesia that must still be proven because there is no researcher who has reported it.

HOXA10 mutations more frequently occurred in patients with endometriosis with less clinical symptoms. In the research reported by $\mathrm{Wu}$ et al. (2008), of 112 patients with endometriosis and 54 controls, $10.24 \%$ of patients were found several heterozygous mutations located in exon 1 and 2 with changes in the amino acid sequence. In another report, Wu et al. (2005) in a study on the promoter and intron 2 and 3 of HOXA10 found the presence of methylation within the promoter and intron 1-2. Lalwani et al. (Lalwani et al., 2008) reported that 56 patients with non-endometriosis were not found mutations in HOXA10.

HOXA10 is needed to increase the endometrial responsiveness to progesterone during the implantation and the decidualization. Resistance to the progesterone explains the disruption of implantation and the failure in endometriosis treatment. The effect of Ser19Cys variant of HOXA10 gene remains to be clarified. We speculate that this variant reduces the ability of protein to bind with gene undercontrolled by HOXA10 such as integrin and other genes encode adhesion molecules. This condition causes decrease in the quality and quantity of pinopodes required for endometrial receptiveness leads to infertility. If it was the fact, as $38 \%$ of infertile endometriosis patients carry this variant, protein study is importent to clarify which gene is affected directly to this conditions. On the other hand, permanent hypermethylation of HOXA10 can cause endometriosis resistance to the treatment and the operative measures. An approach with a gene therapy by manipulating the expression of HOXA10 or with a therapy of demethylation agent improves methylation disruptions and is a potential treatment for endometriosis therapy in the future (Cakmak and Taylor, 2010).

In conclusion, we found a novel heterozygous variant, Ser19Cys, of HOXA10 gene among patients with endometriosis in Indonesian population. The frequency genotype of this variant is $38 \%$ among endometriosis patients but none in control. This variant found in patient with dismenore and endometriosis stage 1 .

\section{References}

Achache, H. and Revel, A. 2006. Endometrial receptivity markers, the journey to successful embryo implantation. Hum. Reprod. Update, 12(6),731-746.

Adam, S.M., Gayer, N., Hosie, M.J. and Murphy, C.R. 2002. Human Uterodomes (Pinopods) do not display pinocytotyic function. Hum.Reprod., 17(1), 1980-1986.

Bagot, C.N, Troy, P.J. and Taylor, H.S. 2000.Alteration of maternal HOXA10 expression by in vivo gena transfection affects implantation.Gene Ther., 7(16),13781384.

Barnhart, K., Dunsmoor-Su, R. and Coutifaris, C. 2002. Effect of endometriosis on in vitro fértilization.Fértil. Steril.,77(6), 1148-55.

Bulun, S.E., Zeitoun, K.M., Takayama, K. and Sasano, H. 2000. Estrogen biosynthesis in endometriosis: molecular basis and relevance.J. Mol. Endocrinol., 25(1),35-42.

Cakmak, H, and Taylor, H.S. 2010. Molecular mechanisms of treatment resistance in endometriosis: the role of progesteronehox gene interactions. Semin. Reprod Med., 28, 69-74

Collette, T., Maheux, R., Mailloux, J., and Akoum, A. 2006. Increased Expression of Matrix Metalloproteinase-9 in The Eutopic Endometrial Tissue of Women with Endometriosis, Hum. Reprod., 21(12),3059-3067.

Daftary, G.S., Troy, P.J., Bagot, C.N., Young, S.L. and Taylor, H.S. 2002. Direct Regulation of $\beta 3$-Integrin subunit gena expression by HOXA10 in endometrial cells. Mol.Endocrinol., 16(3), 571-579.

Gui, Y., Zhang, J., Yuan, L., and Lessey, B.A. 1999. Regulation of HOXA10 and its expression in normal and abnormal endometrium. Mol. Hum. Reprod., 5(9), 866-873. 
Huhtinen, K. (2010) Molecular Profiling of Human Endometrium and Endometriosis. Medica Odontologica.Dissertation. Annales Universitatis Turkuensis.

Kao, L.C., Germeyer, A., Tulac, S., Lobo, S., Yang, J.P., Taylor, R.N., Osteen, K., Lessey, B.A., and Giudice, L.C. 2003. Expression Profiling of Endometrium from Women with Endometriosis Reveals Candidate Genes for Disease-Based Implanation Failure and Infertility. Endocrinology. 144 (7), 2870-2881

Kim,J.J., Taylor,H.S.,Lu,Z., Ladhani,O., Hastings, J.M., Jackson, K.S., Wu, Y., Guo, Kao, L. C. Germeyer,A. Tulac,S. Lobo,S. Yang,J. P. R. Taylor, N. Osteen,K Lessey . B. A. and Giudice L. C. 2007. Expression Profiling of Endometrium from Women with Endometriosis Reveals Candidate Gena for Disease-Based Implantation Failure and Infértilitas.Endocrinology, 144 (7), 28702881.

Klemmt, P.A., Carver, J.G., Kennedy, S.H., Koninckx, P.R. and Mardon, H.J. 2006. Stromal cells from endometriotic lesions and endometrium from women with endometriosis have reduced decidualization capacity. Fértil. Steril., 85, 564-572.

Lalwani, S, Wu,H.H., Reindollar, R.H., Gray, M.R. 2008. HOXA10 mutations in congenital absence of uterus and vagina. Fertil .Steril.89(2), 325-30.

Lessey, B.A., Castelbaum, A.J., Buck, C.A., Lei, Y., Yowell, C.W. and Sun, J. 1994. Further characterization of endometrial Integrins during the menstrual cycle and in pregnancy. Fértil. Steril.,62(3), 497-506.

Matsuzaki, S., Canis, M., Darcha, C., Pouly, J.L. and Mage, G. 2009. HOXA10 expression in the mid-secretory endometrium of infértile patients with either endometriosis, uterine fibromas or unexplained infértilitas. Hum. Reprod., 24(12), 3180-7.

Murphy, C.R. 2000. Understanding the apical surface markers of uterine receptivity. Hum.Reprod., 15(12),2451-2454.
Quinn, C.E. and Casper,R.F. 2008. Pinopodes: A questionable role in endometrial receptivity. Hum.Reprod.Update,15(2), 229-36.

Lee,K.Y. and Mayo, F.D. 2004. Animals models of implantation, Reproduction, 128, 679-695.

Taylor, H.S., Bagot, C., Kardana, A., Olive, D., and Arici,A. 1999. HOX gene expression is altered in theendometrium of women with endometriosis. Hum. Reprod.,14(5),13281331.

Taylor, R.N., Ryan, I.P., Moore, E.S. , Hornung, D., Shifren, J.L., and Tseng, J.F. 1997. Angiogenesis and macrophage activation in endometriosis. Annuals New York Acad. Sci., 828, 194-207.

Wu,N.,Wang, M., Lin, C.Y., and Tsai,H.D.2008, Genetic alterations of HOXA10 and their effect on the severity of endometriosis in a Taiwanese population. Reproductive BioMedicine 16(3),416-424.

Wu, Y., Halverson, G., Basir, Z., Strawn, E., Yan, P. and Guo,S.W. 2005.Aberrant methylation at HOXA10 may be responsible for its aberrant expression in the endometrium of patients with endometriosis. Am. J. Obs .Gyn., 193(2), 371-80. 